\title{
THE USE OF A FORMALISED RISK MODEL IN NHS INFORMATION SYSTEM DEVELOPMENT
}

\author{
Michèle Jeffcott \& Chris Johnson
}

\author{
Department of Computer Science, University of Glasgow \\ 17 Lilybank Gardens, Glasgow, G12 8QQ \\ Email: \{shellyj, johnson\}@dcs.gla.ac.uk
}

\section{Abstract:}

Information Systems (IS) and technology are used extensively throughout the NHS, and the 1998 national information strategy, "Information for Health", sets out how the NHS will be developing and implementing information systems to support patient care within the next decade. This new IS initiative is set against a mixed record of success of IS projects in the NHS, with a number of high-profile failures.

This paper highlights the need to consider the 'organisational issues' involved in systems implementation to avoid failures. It goes on to advocate the use of a process-oriented and organisation studies-based model for risk analysis and management for use in NHS IS projects. Two famous NHS case studies are used to validate the model. It is concluded that there is a real need in the NHS for tools to better control the inherent risks involved in IS development and implementation. Ultimately, the success of IS projects in the NHS is crucial if they want to best utilise clinical and patient information, with the overall aim of improving the efficiency and standard of the nation's health care.

Keywords: Risk assessment; Information systems failure; Organisational issues; NHS Information management

\section{Introduction:}

On the 5 July 1948, the U.K. National Health Service (NHS) was founded to provide comprehensive medical treatment, free of charge, to the British public. More than 50 years on, the NHS has a workforce of over one million people and remains government funded, with a budget of around $£ 42$ billion a year. This makes it a unique healthcare institution when compared to, for example, insurancebased systems in the U.S.A. and Australia. The latest government investment into the NHS involves a modernisation programme costing $£ 140$ million. It is the centrepiece of long-term government funding plans for health, announced on the 5 th November 1999 . The modernisation programme includes $£ 43$ million directed primarily for investment in strategic projects involving new technology. The creation of computer-based information systems (IS) throughout healthcare is a fundamental part of the new technology push. An IS refers to how designed information flows attempt to meet the defined information requirements of an organisation (Willcocks, 1996).

The NHS has long understood the inherent value of information as an important organisational resource. In 1980, the first designated Information Management body was set up. It was known as the NHS Steering Group on Health Services Information. This evolved into several other bodies until in December 1992 the Department of Health launched the Information Management and Technology (IM\&T) Strategy for NHS information systems entitled Getting Better with Information. This initiative has prompted many key changes in information system usage within the NHS. These include more 
systems and terminals, more non-specialist system users, more clinical uses of systems, more sharing of information and finally more networked systems (Barber, 1993). This increasing complexity and reliance on information systems in the NHS is reflected in the latest information strategy, a White Paper introduced in 1998 called simply Information for Health. It is a national strategy designed for local implementation between 1998 and 2005 and sets out how the NHS will be developing and implementing IS to support patient care in the next decade.

The overall aim is to provide NHS professionals with the information they need to provide the best possible care to patients and also to ensure that the public have the information necessary to make decisions about their own treatment and care. A vast amount of information is potentially useful for these purposes. This information strategy should ensure that the most useful information is captured in the most convenient way and is as accurate and up to date as possible. This is important in terms of NHS management, ensuring the availability of accurate information for managers and planners to support local Health Improvement Programmes and the National Framework for Assessing Performance

Much of the Information for Health strategy relies on the proper functioning of information systems within hospitals and clinical practices. Large amounts of public funds are being utilised to achieve this. In 1998-1999 the U.K. government spent $£ 1$ bn out of a total of $£ 7.1$ bn on health care information systems. However, the NHS's recent history of common IS failures raises some concerns. In the 1980's and 1990's, the NHS was rocked by some high profile and high cost IS failures. These resulted in significant losses for an organisation already strapped for cash. Willcocks and Griffith's (1997) report that risks in NHS information systems projects continue to be underestimated and that failures are still very common.

This paper argues that given the scale of public resources invested, the NHS must improve their current understanding of the risks involved in IS projects. In particular, the following sections introduce the importance of careful consideration of complex organisational issues when developing and implementing information systems. This paper goes on to advocate the use of a formalised risk assessment model to enable better identification and avoidance of these underlying risks. The cost argument alone justifies the use of risk assessment carried out in NHS information systems development to improve the chances of successful implementation and functional longevity.

\section{The Reality Of Risk:}

Risk is inherent in all major organisational projects. Based on Loudon and Loudon (1991) risk is taken to be a negative outcome that has a known or estimated probability of occurrence based on experience or some theory. However, it is important to add that "risk of a negative outcome only becomes a salient problem when the outcome is relevant to stakeholder concerns and interests. Different settings and stakeholders will see different outcomes as salient." (Willcocks \& Margett's, 1994). Stakeholders are all individuals that are or could be affected by the system.

Willcocks and Griffiths (1997) reviewed the main research studies on risk and concluded that prominent projects commonly experience overruns, are often over budget, do not perform in the way expected, or are cancelled prior to their completion after the expenditure of considerable sums of money (Appleton, 1991; Collingridge, 1992; Davidson \& Huot, 1991; Morris \& Hough, 1987). Risk levels are further heightened when working with new technology, as affects on timing, costs and 
delivery deadlines are exacerbated (Hochstrasser \& Griffiths, 1991). Indeed a range of studies show that the IT component adds a different dimension of risk which all too often can tip the balance towards project failure, rather than towards project success.

However, risks in computer-based IS projects continue to be under-managed. Research studies have shown that the result of this is that over $20 \%$ of IS expenditure is wasted and between 30 and $40 \%$ of IS projects realise no net benefits, however measured (Willcocks, 1993). 'Failure' is not a simple concept, ranging as it does from cancellation or termination, through late delivery and cost overruns, through to non-compliance with specifications and/or the demands and expectations of clients and users. Therefore, looking at IT failure more specifically, a 1998 review of 100 failed IT projects revealed that $87 \%$ exceeded their budgets by more than $50 \%$ while $45 \%$ of the projects failed to produce the expected results (KPMG survey, Toronto 1998).

\subsection{The Cost Of IS Failure In The NHS:}

The under-management of risks in IS projects is very surprising considering the size of IT expenditure, and the history of disappointed expectations is considered (Keen, 1991; Hochstrasser \& Griffiths, 1991; Willcocks, 1994; 1996). This is particularly relevant to the NHS which has continued to invest highly in IS projects, in the face of well-documented failures. John Bourn, the then Comptroller and Auditor General, supports this in his 1991 report Managing Computer Projects in the National Health Service. He states that there is "considerable weaknesses in the management, project and financial control of particular information technology projects, including a computerised information system in the Wessex region."

The two case studies below help to illustrate the huge financial drain of IS failure in the NHS, and stress the importance of better assessing and managing the risks involved. But better risk analysis techniques in IS failure is not purely a cost-argument alone. The ineffective collection and transfer of information in healthcare may also result in harm to patients.

1) The Wessex Regional Health Authority Regional Information Systems Plan (RISP), aimed to achieve integration across the health region, and began in the mid-1980's. The IS plan envisaged the development of 5 core computer systems covering hospital information, manpower estates, community care and accountancy, operating to common standards and in every district region. Development was to be completed within 5 years at an estimated cost of $£ 25.8$ million (at 1984/1985 prices), with associated revenue costs over the 5-year period of $£ 17.5$ million. In April 1990, when the project was officially abandoned at least $£ 43$ million had been spent. However, Wessex Health Authority management only admitted to $£ 20$ million wasted over the 6-year period.

2) The main objective of the London Ambulance Computer Aided Despatch (LASCAD) project was to automate many of the human-intensive processes of manual despatch systems associated with ambulance services in the U.K. The London Ambulance Service (LAS) spent a lot of money in the 1990's in order to implement an effective Computer Aided Despatch (CAD) project. LAS scrapped a development by IAL (BT subsidiary) at a cost of $£ 7.5$ million in October 1990. In June 1991, they signed a $£ 1.1$ million contract with Systems Options to provide a CAD. This attempt famously failed on 27 th October 1992.

These case studies demonstrate that an NHS organisation, when considering its strategy and plans for procurement and implementation of information systems solutions, must have regard to the potential 
for failure and the factors that cause projects to fail. More importantly, the NHS must continually assess these risks and ensure steps are taken to maintain risk at an acceptable level, and that procedures are in place to ensure that controls are implemented effectively and remain expedient over time.

The London Ambulance and Wessex failures were chosen as the primary case studies in this paper for a number of reasons. First, as a result of being highly publicised and costly NHS failures, they were comprehensively investigated, culminating in official government reports being produced. These provide a deluge of primary evidence, which is vital for careful examination of the circumstances of the failures. Second, although they occurred a decade ago, they are representative of the types of IS failures that continue to occur in the NHS today. Recent healthcare failures include the Hospital Information Support Systems Initiative in 1997 and the Clinical Coding Information System in March 1998. Both systems were abandoned before implementation despite many years of work and investment. The London Ambulance and the Wessex Project failures were therefore not only seen to be representative of the current problems that the NHS have, when developing healthcare IS, but also provide us with thorough evidence which the latter failures do not, due to their recency and lack of press attention.

The ultimate problem of IS failure in the NHS is that lessons about the nature of risks detrimental to projects are still not being effectively integrated into policy. Despite continual new initiatives from the government, such as the new e-government strategy, A strategic framework for public services in the Information Age, introduced in June 2000, the success rate of IS projects in the NHS is still very low. The need to improve the success of IS projects in the NHS, by better understanding and managing the risks involved, still remains an issue of paramount importance.

\subsection{Current NHS Approaches to Risk:}

Risk management is concerned with adverse events, the likelihood of outcomes to otherwise intended events, and the application of measures to eliminate or control these risks. The NHS does have a risk management strategy, but it underestimates the risks involved in the adoption and implementation of new technologies. This is because the NHS's risk management strategy was born in response to increasing financial pressures from litigation for clinical negligence. In 1975, the cost of clinical litigation in the NHS in England alone was around $£ 1$ million; by 1990, survey data suggests the cost had risen to around $£ 50$ million; in 1996 the costs were about $£ 200$ million (Dingwall \& Fenn, 1995; Evans, 1998). Both the volume of litigation and the size of financial settlements and awards were rapidly increasing, and a continuing rise of up to $25 \%$ a year has been forecast (Evans, 1998).

Following the 1998 government paper a New NHS: modern, dependable, a five-year risk management strategy entitled Controls Assurance based on 150 risk management standards was introduced. These standards were designed to "assist NHS staff, including Chief executives and board members, to identify risks, to determine unacceptable levels of risk, and then decide on where best to direct limited resources to eliminate or reduce those risks." The strategy centres around the concept of clinical governance: "a framework through which NHS organisations are accountable for continuously improving the quality of their services and safeguarding high standards of care by creating an environment in which excellence in clinical care will flourish."

The strategy involves some clinical risk assessment and widespread incident reporting. However, it focuses on better procedures for dealing with legal claims for clinical negligence when they occur, gathering evidence, making an early assessment of liability, and then acting more speedily to settle or 
defend claims. There is no real scope for the risks involved in the introduction of new technology projects, including information system implementation, despite the fact that assessment of risks in this area are crucial to the management and control of large-scale IT projects.

In June 1999 though, the NHS Information, Management and Technology (IM\&T) Strategy introduced a project timetable for a new 'Risk Register'. Unlike, the broader clinical governance schemes, this project aims to directly address the issue of risk within IM\&T business cases, and IS and IT projects throughout the NHS. The risk register was initiated to examine the prospects of developing and implementing a means of gathering and disseminating the experience of NHS IM\&T projects in coping with risk. The aim is to see whether and how such information can be provided in a standardised, consistent and structured risk register, to help organisations to determine how best to relate the experience of others to their own circumstances and in turn to feed back their own experience.

Because the risk register is still in its development stages, it is yet to be seen whether it will be successful. The idea to comprehensively document past experience and risk in IS projects to help to stop certain common risks being overlooked, is certainly a promising one. The risk register will hopefully represent the wide-range of risk factors that cause failure in IS projects, involving all elements of the technological, human and organisational systems.

Another possible approach is the use of risk assessment in the NHS IS projects. Risk assessment techniques provide a means of assessing the threats that are posed to a system and so can be used to prioritise any response from designers, operators and regulators. Risk assessment techniques are now well established in many public sector industries, such as finance and social services, but they have not been evaluated for widespread use in the NHS. The NHS Executive, set up to provide clear strategic leadership, documents that presently risk assessment is a task that is not well understood in the NHS. They report that it is only carried out "because we have to include it in the business case" rather than because it is recognised as a central task of successful project planning and management. Pike and Ho (1991) add that there is a general lack of managerial use of risk analysis in capital budgeting decisions to the detriment of IT projects. Despite current reluctance, there are a number of different models, generated from research and experience, that could be used by the NHS to assist risk assessment at the feasibility stage of IS projects.

\section{The Importance Of 'Organisational Issues' In Risk Assessment:}

Before an overview of these risk assessment tools, it is important to introduce the crucial role that 'organisational issues' play in IS development. Lyytinen and Robey (1999) report that failures remain common despite advances in development tools and technologies. Risk assessment models can be used to reduce risk. Risk assessment is the process involved in estimating the degree of risk associated with a given project, usually at the feasibility stage of development (Beynon-Davis, 1999). However, Lyyntinen (1987) points out that a narrow focus on risk techniques blinds participants to the organisational context, which is exactly where many projects encounter their most serious difficulties.

There is a growing realisation that organisational issues play a substantial, if not primary role in systems failure (Long 1987; Kearney, 1990; Buchanan, 1991). Most recently, Doherty and King (1998) state that a lack of consideration of organisational issues in systems development can lead to project failure. Although there have been few attempts to explicitly define the term organisational issue, they have been defined by providing examples of 'non-technical' aspects of systems 
development, which might have an impact on the ultimate success or failure of a project (Eason, 1988; Clegg et al., 1989). Recently, Ewushi-Mensali and Przasnyski (1994) found that organisational factors, particularly the amount of senior management involvement and the degree of end-user participation in the project development were the most widespread and dominant factors contributing to IS failure. Mackenzie (1994) in his comprehensive survey of computed-related accidental death stated that: "To make computer systems safer, we need to address not merely their technical aspects, but also the cognitive and organisational aspects of their 'real-world' application."

Despite the recognised importance of organisational issues, research shows that systems development is still 'technology led', that organisational issues are not properly addressed during the systems process (Clegg et al., 1994; 1997), and that much of the responsibility for this rests with IT professionals. Hornby (1992) adds that "Systems analysts do not claim to have knowledge of organisational issues in IT systems, and there is no evidence that they are encouraged or rewarded for considering such issues." This technical orientation of systems development methodologies has typically resulted in the approach of implementing a system, and then trying to cope with its organisational implications. If a risk assessment framework is to be used effectively in NHS IS projects, then it must be designed to take into account the context, history and organisational processes within the health service.

\section{An Overview Of Risk Assessment Models:}

There have been a number of risk assessment models developed specifically to analysis IS project risk. Although most outline important characteristics of risky IS projects, not all reflect the importance of organisational issues and the overall environment and context within which the IS needs to function. Environment and context are two important concepts, which need to be thoroughly analysed and accommodated in design, if an IS is to function successfully within an organisation.

A general definition of environment, in the Merriam-Webster dictionary, is "the circumstances, objects, or conditions by which one is surrounded. " An organisational environment is the aggregate of social and cultural conditions that influence the life of an individual or community. Context is defined, again in Merriam-Webster, as "the interrelated conditions in which something exists or occurs." Applying this in an organisational sense, context encompasses all the factors outside the control of risk assessment, the structure and culture of the organisation that can not, if at all, be easily changed.

The environment and context of the NHS are very unique, when compared to other industries. The NHS is a non-profit motivated organisation, involving many different groups which each have different responsibilities and roles. These are the Government, the NHS Executive, NHS Health Authorities, NHS Trusts, Primary Care Groups and Social Service organisations. Beynon-Davis (1994) points out that the effect this has on computing within the NHS is that no one body has overall responsibility for IT. Therefore, the context of NHS computing is that it remains problematic due to the absence of a clear, strategic vision for IT. The overall structure of the NHS environment is semi-hierarchical. It is becoming increasingly decentralised with, for example, NHS trusts being given more autonomy over budgeting and resource allocation. A risk assessment technique for use in the NHS should reflect its uniqueness, and thoroughly take into account the constantly evolving management and power structure that exists within the organisation as a whole. Therefore, a risk assessment model that focuses on technical risks and neglects organisational factors would be unsuitable for NHS IS projects. 
The earlier risk assessment models concentrated very much on technical factors as the basis for IS failure. Earl's (1989) attempt proposed a rigid cost-benefit framework for assessing on economic, technical and operational criteria the viability, risks and opportunities represented by the IT investment. Corder (1989) suggested that high risk factors as project size, project definition, user commitment and stability, project time, and the number of systems interfaces. Cash, McFarlan and McKenney (1992) refined this approach suggesting that the three most important dimensions that influence the risk of a development project: project size, experience with the technology and project structure. In general, the smaller, more experienced and more highly structured the project then the less risk is associated with it. Parker et al.'s (1988) model at least elucidated toward organisational risks, looking at how well equipped the organisation is to implement the project in terms of personnel, skills and experience. But the problem was that this was too truncated an assessment of organisational risk (Willcocks, 1992). A more detailed, process-orientated approach to organisational risks in IS projects was needed.

This came in response from increasing research that stressed that major reasons for IS failure tend to be through organisational, social and political, rather than technical factors (Scott-Morton, 1991; Willcocks, 1992). And as a result, Willcocks and Margett's (1994) recent risk assessment model was developed, which regarded these organisational issues as central to the understanding of IS project risk and general failure.

\subsection{Willcocks And Margett's Risk Assessment Model:}

The basis of Willcocks and Margett's Risk Assessment Model came from work by Pettigrew et al. (1991, 1992) which endeavoured to avoid "the ahistorical, aprocessual, and acontextual character of much research on organisational change." Applying this premise, Willcocks and Margetts developed six conceptual, inter-playing categories can be brought into analysing the development, introduction and use of information systems:

1) History: Prior organisational development, e.g. relevant IS experience and organisational history and most importantly, IS success or failure.

2) Internal Context: The characteristics of the organisation itself, e.g. strategy, structure, reward system, management, human resources and industrial relations arrangements, IS infrastructure and management.

3) External Context: The givens that an organisation and its members need to respond to and accommodate, e.g. the economy, political and governmental policy, markets, competition and, in the public sector, department or local government guidelines, procedures and funding arrangements.

4) Content: The changes involved in and substance of a project, e.g. size and complexity of project, technical uncertainty, whether radical or incremental in impact.

5) Processes: How things are done and the issues perceived, e.g. project management, project team experience, staffing stability, user commitment.

6) Risk Outcomes: Planned or unanticipated, desirable or otherwise, e.g. cost, time, technical performance, operational efficiency, user acceptance. 


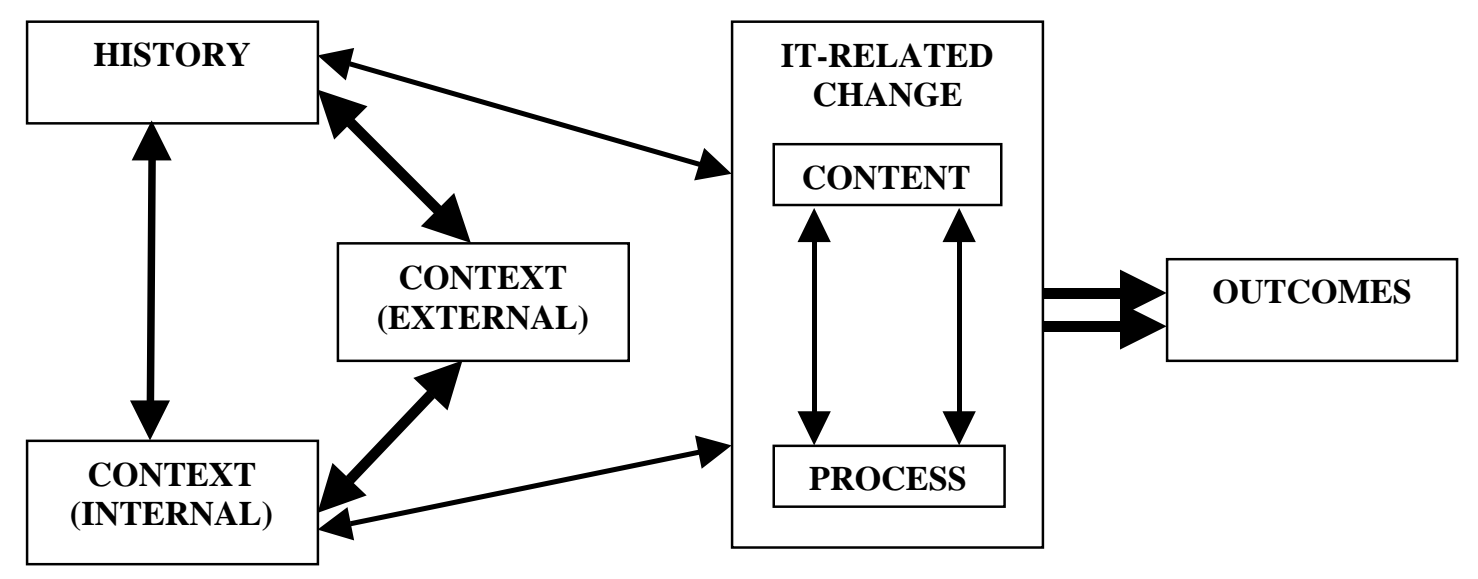

Figure 1. The 6 inter-playing factors in the model for risk assessment

\subsection{Probabilistic Risk Assessment:}

\subsubsection{Introduction:}

Willcocks and Margett's (1994) model, with it's focus on environment and context, is in contrast with other established risk assessment methods such as Probabilistic Risk Assessment (PRA). PRA is an integration of several techniques that aim to quantify and assess the potential for failure and to help find ways to reduce risk. However, although effective at revealing technologically centred failures, most PRA techniques do not provide any explicit means of representing organisational or human factors failures (Johnson, 1998). Also, PRA was designed to be performed in industrial and engineering environments, and so it is unlikely if it would be applicable to the NHS for use in assessment of hospital information systems. The various PRA techniques examined below serve to reveal how established forms of risk assessment generally neglect the organisational considerations involved in the implementation and running of systems.

\subsubsection{Hazards and Operability Analysis (HAZOP):}

Hazard and Operability (HAZOP) analysis is the most widely used and recognised as a preferred PRA approach by the chemical process industries. HAZOP analysis is the study of systematically identifying every conceivable deviation from the design intent, and all possible abnormal causes, and adverse hazardous consequences that can occur in a chemical plant. However, it is well known as a difficult, labour- and knowledge-intensive, and time-consuming analysis. HAZOP analysis is typically performed by a group of experts pouring over the process for weeks. A typical HAZOP study can take 1-8 weeks to complete, costing about $\$ 10,000$ per week. It is estimated that $\$ 2$ billion was spent collectively by the US process industry between 1995-97, on HAZOP studies alone. Given the enormous amounts of time, effort and money involved in HAZOP reviews, it seems that it would be a very inappropriate technique to apply to an already over-burdened, and under resourced organisation such as the NHS. 
Also, Redmill et al. (1999) question it's effectiveness, as they believe "that where HAZOP is employed it often does not fulfil its potential because of incorrect use." They add that this may be the reason why it remains untouched in many industries. However, most detrimental to HAZOPs possible application to the NHS, is that although it covers equipment failures and human errors well, it is unusual for it to consider deviations related to organisational factors within information and management systems (Suokas, 1989).

\subsubsection{Failure Modes, Effect and Criticality Analysis (FMECA):}

Failure Modes, Effect and Criticality Analysis (FMECA) stems from Failure, Modes and Effects Analysis (FMEA). FMEA was developed by reliability engineers to permit them to predict equipment reliability. Leveson (1995) therefore describes it as "a form of reliability analysis that emphasises successful functioning rather than hazards and risk." The goal is to establish the overall probability that the product will operate without a failure for a specific length of time or, alternatively, that the product will operate a certain length of time between failures. The first step in FMEA is to identify and list all components and their failure modes. For each failure mode, the effects on all other system components are determined along with the effect of the overall system. Then the probabilities and seriousness of the results of each failure mode are calculated.

FMECA extends FMEA with a more detailed analysis of criticality of the failure. Criticality rankings are generally expressed as probabilities or frequencies. Along with the ranking a description is provided of the preventive and corrective measures that should be taken and the safeguards to be incorporated.

FMECA is similar to HAZOP in that it neglects the human and contextual factors. Hammer (1972) points out that FMECAs pay little attention to human errors in operating procedures, hazardous characteristics of the equipment, or adverse environments. Also, although environmental conditions are considered in identifying the stresses that could cause hardware failure, the probability of occurrence of such environmental stresses are rarely used.

\subsubsection{Human Reliability Analysis (HRA):}

Human Reliability Analysis (HRA) is the method by which the probability of a system-required human action, task, or job will be completed successfully within the required time period and that no extraneous human actions detrimental to system performance will be performed. The results of HRAs are often used as inputs to the PRA process.

The first attempt to create an HRA method, which attempted to integrate human factors assessments into PRA was the Technique for Human Error Rate Prediction (THERP). THERP presents a model of organisation through the "Performance Shaping Factors"(PSFs) which allow consideration of factors affecting the human operator's performance (Swain \& Guttman, 1983). However, THERP only focuses on the external actions and consequences of this performance, ignoring high level errors in cognition, understanding and mental representation of the system and physical phenomena.

A Technique for Human Event Analysis (ATHEANA) goes beyond THERP in its capability to account for and predict human errors, by examining cognitive processes (Barriere et al., 1998). ATHEANA extends an examination of simple PSFs by looking to error-forcing contexts, unsafe actions and plant conditions as other framework elements for full safety assessment. With its focus on the context within 
which the operators must act as well as on the error mechanisms, it represents an important paradigm shift from a focus on "human error." However, the definition of an error-forcing context is ambiguous in the ATHEANA method. It is defined as "the combined effect of PSFs and plant conditions that create a situation in which human error is likely." Yet in Chapter 10 of NUREG-1624, Revision 1, it is stated that an error-forcing context may be "so non compelling that there is no increased likelihood of the unsafe act compared with the routine PRA context." This may just mean a refinement of the terminology, however, an official sub-committee on human factors reviewing the ATHEANA methodology in November 1999, found a more problematic flaw with the error-forcing context. They concluded that the search for error-forcing contexts is a major resource intensive effort, requiring a multidisciplinary team of experts, which is potentially inappropriate for all unsafe acts. Therefore this attempt to delve into contextual factors appears to be insufficient to provide an extensive examination of the inherent risks in the organisational environment in which a system resides.

Newer approaches, such as MERMOS (Bieder et al., 1998), are the next generation of HRA techniques that aim to more closely integrate the human and organisational factors. But these need more empirical evidence to prove whether they actually succeed in this aim. Also, they will need to be adapted to cope with the unique organisational factors that differentiate the specific "healthcare conditions" from the existing industrial "plant conditions" that these methodologies currently cater for.

\subsubsection{Summary:}

Probabilistic risk assessment techniques do not support a comprehensive analysis of IS risks and failure. When examining accidents, Hollnagel (1993) reported that organisational and human factors problems, at the distal end, are being hidden behind operator error and other proximal factors. Similar problems occur when looking at PRA. For example the HAZOP process stops when more proximal factors such as pump failure are uncovered, without the necessarily tracing back to a maintenance error, and perhaps back from that to a management problem. And although THERP attempts to model human and environmental factors, it fails to link them with failures in the technical systems (Leveson, 1995). Also, the more recent so-called cognitive methods, such as ATHEANA and MERMOS, have yet to reveal whether they will successfully integrate the human and organisational elements of in systems safety analysis. IS failure is multi-factorial in nature, involving deficiencies in the technical, human and organisational systems. Therefore by not adequately accounting for the organisational factors involved in the environment and context of an IS, PRA is lacking as a risk assessment technique.

Leveson (1995) reveals that policy and principles of management, organisational structure, training factors, and the safety of the engineering process employed are just some of the organisational factors that PRA neglects. She believes that PRA has "an inability to represent these particular (organisational) aspects of the system or to evaluate them in the analysis." Therefore, to conclude, PRA techniques are too technologically centred to be of use to assess risks in the NHS, where organisational change is common and the general importance of organisational dynamics is paramount. Willcocks and Margett's (1994) model seems much more suitable for possible use in NHS IS projects. 


\section{Application of Case Studies to Willcocks and Margett's Model:}

\subsubsection{Background:}

Willcocks and Margett's (1994) originally applied their model to a number of IS projects in different domains, such as local government, the electronics, and manufacturing industry. The two case studies to be examined here are the Wessex Regional Health Authority Regional Information Systems Plan (RISP) and London Ambulance Computer Aided Despatch (LASCAD) project. The following sections go on to use Willcocks and Margett's model (see Figure 1) to analyse these previous instances of failure within the UK NHS.

Willcocks and Margetts believe that the strength of case study analysis is that it can demonstrate the linkages and mutual influence of categories in their model. This paper seeks to emulate this and provide evidence to illustrate our general arguments about IS failure.

\subsubsection{Content:}

The changes involved in and substance of a project, e.g. size and complexity of project, technical uncertainty, whether radical or incremental in impact.

\subsubsection{The Wessex Regional Health Authority Regional Information Systems Plan (RISP):}

In May 1984, the RISP was adopted by the Wessex Regional Health Authority (WRHA). Its overall aim was described as: "To use modern technology in order to optimise the use of information in the continuous improvement of the effectiveness and efficiency of clinical and other health services." In brief the plan proposed:

- The development of "five major systems, operating to common standards and operational in every district of the region." The five core systems were Accountancy, Manpower, Hospital, Estates and Community.

- Development was to be completed within five years at an estimated capital cost of $£ 25.8$ million (at $1984 / 84$ prices) with associated revenue costs over the five-year period of $£ 17.5$ million.

- A transitional strategy to make the most of existing systems, provided they worked well and could be integrated with the RISP in due course.

- Any interim systems to make use of proven software and systems and packages available form elsewhere; and

- The devolution of responsibility for the operational management of systems from the region to district.

\subsubsection{The London Ambulance Computer Aided Despatch (LASCAD) project:}

The major objective of the LASCAD project was to automate many of the human-intensive processes of manual despatch systems associated with ambulance services in the U.K. The LASCAD system was built as an event-based system using a rule-based approach interaction with a geographical information 
system (GIS). The system was built using GIS software (WINGS) running under Microsoft Windows. The GIS communicated with Datatrak's automatic vehicle tracking system. The system ran on a series of network PCs and file servers.

The basic functionality of the intended LASCAD system was as follows: British Telecom (BT) operators would route all 999 calls concerning medical emergencies as a matter of routine to LAS headquarters (HQ) in Waterloo. 18 HQ 'receivers' were then expected to record on the system the name, telephone number and address of the caller, and the name, destination address and brief details of the patient. This information would then be transmitted over a local area network to an 'allocator'. The system would pinpoint the patient's location on a map display of areas within London. The system was expected to monitor continuously the location of every ambulance via radio messages transmitted by each vehicle every 13 seconds. The system would then determine the nearest ambulance to the patient. Experienced ambulance dispatchers were organised into teams based on three zones (south, north-west and north-east). Ambulance dispatchers would be offered details of the three nearest ambulance by the system and the estimated time each would need to reach the scene. The dispatcher would choose an ambulance and send patient details to a small terminal screen located on the dashboard of the ambulance. The crew would then be expected to confirm that it was on its way. If the selected ambulance was in an ambulance depot then the despatch message would be received on the station printer. The ambulance crew would always be expected to acknowledge a message. The system would automatically alert HQ of any ambulance where no acknowledgement was made. A follow up message would then be sent from HQ. The system would detect from each vehicle's location messages whether an ambulance was heading in the wrong direction. The system would then alert controllers. Further messages would tell HQ when the ambulance crew had arrived, when it was on its way to a hospital and when it was free again.

\subsubsection{Summary:}

By examining Content, it can be argued that the impact of both RISP and LASCAD were high risk. RISP adopted a radical approach, starting with a detailed analysis of the information needs of the hospital and community services, leading to the production of data models of how the needs could be met. The means of meeting those requirements would then be determined which was a misguided proposal leaving much ambiguity in the project strategy. There were similar risks in the LASCAD approach. The early decision to achieve full CAD implementation in one phase was very unrealistic. In an implementation as far reaching as CAD it would have been preferable to implement a step-wise approach, proving each phase totally before moving on to the next. The LASCAD report states that "the size of the programme and the speed and depth of change were simply too aggressive for the circumstances."

\subsubsection{History:}

Prior organisational development, e.g. relevant IS experience and organisational history and most importantly, IS success or failure.

\subsubsection{Organisational History:}


Despite almost a decades difference in their introduction, RISP and LASCAD were both fundamentally influenced by the government's October 1983 Griffith's Report on Management in Health Authorities. The report led to the establishment of the NHS Management Board, emphasising the need for general managers and the devolution of management responsibilities to all levels. It also led to corresponding changes in health authority structures. In the new organisations, with new levels of management, there was an increased demand for information and also a greater recognition of the need to manage information as a resource. Since that time the NHS Management Board and their predecessors the NHS Executive, have promoted a concerted approach to the development of IS and the use of IT in the hospital, community health and related services. However, whilst there has been a recognition that effective IS are required to support many of the NHS reforms; the ability of the NHS to achieve the benefits of such an approach have been less successful. Notable factors include: a lack of coordination; lack of effective management and project control; little attempt to cost justify IT; too much reliance upon suppliers; lack of experience/appropriate staff; and a general lack of training.

\subsubsection{Previous IS experience:}

In terms of IS experience, the Wessex Regional Health Authority Regional Information Systems Plan (RISP) was the first project of its kind in the Wessex Regional Health Authority (WRHA). However, the London Ambulance Service (LAS) had had an experience of an IS failure. It previously scrapped the Intel Architecture Labs (a BT subsidiary) development at a cost of £7.5 million in October 1990. This project is reported to have been late starting in May 1987 after a delay of 1 year. The reason for scrapping this earlier project revolved around a debate over faulty software. The LAS sought damages from IAL for a faulty despatch module in October 1990. Unlike this IS failure experience, the 1992 LASCAD failure, was not purely a technical failure (Beynon-Davies, 1999). Therefore, the experience of the 1991 failure was very different, with organisational issues not seen as playing a major role. As a result, although LAS were able to learn technical lessons, this experience did not shed any light on how to better manage organisational risks in IS projects.

\subsubsection{Summary:}

Examining History has shown that the introduction and subsequent failures of RISP and LASCAD must be seen in the larger web of the difficulties the NHS faced in achieving a co-ordinated policy towards IS development and implementation. It also highlights that many risks experienced by Health Authority IS projects relate strongly to environmental pressures and constraints within the overarching NHS organisation. In terms of prior IS project experience, despite the WRHA's lack of experience and LASCAD's negative 1990 attempt to launch a system, it appears that necessary caution and attention to possible risks was not taken when developing the new projects.

\subsubsection{Internal Context:}

The characteristics of the organisation itself, e.g. strategy, structure, reward system, management, human resources and industrial relations arrangements, IS infrastructure and management. 


\subsubsection{The IS Strategy at Wessex RISP:}

As this was the first large IT venture that RISP had ever undertaken, it is surprising that it was quite so ambitious, and consequently risky. In the autumn of 1982, RISP was launched. The aim was to formulate a strategy to co-ordinate the procurement of computer hardware and the design of software to cover all aspects of information requirements in Wessex. The Chairman of WRHA had been convinced for some time of the need for a co-ordinated approach to the development of IT within the region. Hence, the emphasis was to be on integration: all systems were to be accessible from any terminal connected to the network and data in any one application system could be accessed automatically by any other, as necessary. In light of the chequered history of the NHS IS policy, outlined above, it seems unwise that RISP went for such a bold strategy.

\subsubsection{Management and Industrial Relations involved in LASCAD:}

The internal context behind the LASCAD project also involved high risk, in regard to management structure and staff relations in LAS. The LASCAD report states that "poor communication between staff and staff associations and senior LAS managers created an atmosphere of mistrust." Also, the report records that "Hardware and software suppliers dealing with LAS spoke of disorganisation, low staff morale, friction between management and the workforce, and an atmosphere of hostility towards computing systems." One of the main reasons for the low staff morale may be that the control room staff had little previous experience of using computers (New Scientist, 1992). The union NUPE referred to a 'macho' style of management at LAS. The Labour party's health secretary, David Blunkett, eventually demanded a public inquiry into the system, but not until September 1992. This meant that the damage was already done in terms of the poor fit of the IS to the organisational environment and users of LASCAD. The LASCAD report recommended that "there is a need to develop quickly an effective partnership between executive management and trade unions."

\subsubsection{Summary:}

In both RISP and LASCAD, there were flaws in primary aspects of Internal Context, which illustrate how risks inherent in the inappropriate organisation of the IS function can occur from within. These need to be addressed in IS design and development to avoid failures.

\subsubsection{External context:}

The givens that an organisation and its members need to respond to and accommodate, e.g. the economy, political and governmental policy, markets, competition and, in the public sector, department or local government guidelines, procedures and funding arrangements.

\subsubsection{The Wessex RISP:}

Investment in computer systems in the NHS has risen rapidly over the last four years, however at the time that RISP was conceived in 1982, the need for greater investment had only just been recognised. The recognition that computers could bring significant benefits in terms of accuracy, completeness and timeliness of information was understood but there was, at that time, no clear and agreed national 
framework for information management. Until 1986 the Department of Health's (DOH) IT policy allowed each regional health authority to develop its own IT services and decide what hardware and software to buy, within the framework of broad national guidelines and international rules. The role of the DOH was to develop and advise on strategic and policy issues and the performance of major tasks. Therefore RISP should have been recognised as a high risk project, seeings it was left to a health authority with no previous IS experience and in an environment where most of the responsibility for technology procurement, project management and budgeting was left firmly on WRHA's shoulders.

\subsubsection{The LASCAD project:}

By the time the LASCAD project was introduced in June 1991, major NHS reforms had taken place. The 1989 White Paper called Working with Patients and the 1990 NHS Community Care Act led a major restructuring and culture change initiative. The reforms, which affected the LAS, were precipitated by the fact that during the 1980's NHS management failed to modernise the service effectively. There was a lack of investment in the workforce (such as paramedic training), the fleet and the estate. The final push for reform came at end of the 1990's, at the end of a protracted national pay dispute, where it was clear that the LAS needed major modification and change. The NHS initiatives intended to revitalise LAS management. During the period between January and April 1991 the numbers of senior and middle management posts within the LAS were reduced by 53. The LASCAD report found that "The NHS was involved in only sparse consultation with staff over this restructuring and the whole process caused a great deal of anxiety."

The report stated further that "Management clearly underestimated the difficulties involved in changing the deeply ingrained culture of the LAS, and as a result the NHS agenda for LASCAD was far too aggressive" and "The size of the programme and the speed and depth of change were simply too adventurous." Willcocks and Margett's (1991) findings support this as they report that in situations diagnosed as low risk, that is with much support for IT adoption from within the health authority, risk can be re-introduced by financial and time constraints imposed by central government that do not reflect the realities of project managing robust, usable systems into the organisation. Indeed, this was the case with LASCAD, as the LAS management were continually under undue pressure from the NHS to ensure that the LASCAD system was implemented on time and within budget. This pressure and a fear of failure blinded them to some of the fundamental difficulties of the system implementation. The LASCAD report states that "many LAS managers and staff saw deadlines set by the top level management as being rigid, inflexible, and, more importantly, not to be challenged."

\subsubsection{Summary:}

Examining the External Context reveals that both RISP and LASCAD suffered due to problems and changes that were occurring within the outer context of the NHS as an organisation - deficiencies in government policy and higher management. These were factors which were beyond the control of the WRHA and LAS, but which were detrimental to their IS projects. The lesson to learn is that although the external context is beyond the control of Health Authorities and Trusts, as they develop IS and other IT projects, developers should factor in these external activities and controls when designing the IS. For example, project managers need to adapt their implementation schedules to accommodate structure changes and unsupported IS projects need to be scaled down to minimise potential risks. 


\subsubsection{Processes:}

How things are done and the issues perceived, e.g. project management, project team experience, staffing stability, user commitment.

\subsubsection{The LASCAD Project:}

LAS failed to follow the PRINCE Project Management Method in the set up and operation of an IT executive committee, project board, project management team and project assurance team. As a result, "the project management throughout the development and implementation process was inadequate and at times ambiguous". The LASCAD report advised that "A major systems integration project such as CAD requires full time professional, experienced project management." Evidence that this was lacking was seen in many very ill advised decisions and mistakes that the LAS made, which greatly increased the risks faced by the LASCAD project and contributed to it's eventual failure. Examples include:

- LAS management chose an inappropriate supplier which was detrimental to the project:

"In awarding the contract for CAD to a small software house, with no previous experience in similar emergency service systems, LAS management were taking a high risk."

"The project team did not show, or discuss with, the LAS Board independent references on the lead CAD contractor that raised doubts on their ability to handle such a major project."

"The LAS board gave a misleading impression, by the project team, of the previous experience of the lead contractor in emergency service systems."

"The South West Thames Regional Health Authority procurement rules were followed fully, but these rules emphasised open tendering and the quantitative aspects of procurement(obtaining the best price) rather than the qualitative aspects (who will do the job best?)."

- Blindly sticking to such a tight schedule meant that the CAD system was not fully tested to a satisfactory level of quality and resilience before full implementation on 26 October 1992. This obviously contributed to the systems failure.

"LAS management ignored or chose not to accept advice provided to it from many sources outside of the Service on the tightness of the timetable or the high risk of the comprehensive systems requirement."

- At no time was user commitment addressed. Ignorance of this important organisational issue increased the risk of the project:

"There was "incomplete ownership" of the system by the majority of the users. The many problems identified with the many of the system components over the preceding months were not dealt with adequately, and the staff had no forum to voice their concerns and opinions to LAS management."

"Training provided to CAC staff and ambulance crews was incomplete and inconsistent."

This lack of consultation with users and acknowledgement of their feedback instilled an atmosphere of system detachment and distrust in which staff expected the system to fail rather than willing it to succeed. The unsatisfactory training of staff exacerbated this. 
- The issue of adapting work practices to the new CAD was also neglected:

"For satisfactory implementation of the system to occur changes to a number of work practices was necessary. Senior LAS management believed that implementation of the introduction of the system would, in itself, bring about these changes. In fact many of the staff found it an operational "strait jacket" within which they still tried to operate local flexibility. This caused further confusion within the system."

\subsubsection{The Wessex RISP:}

The RISP case study involved a similar catalogue of inadequate management initiatives, increasing the risks and developing flaws in the IS project. In May 1984 the WRHA set up a regional information group of district representatives at Chief Officer level to agree priorities and policies for the implementation of the regional information systems plan. The region also set up small project groups to oversee the successful completion of core and other large system projects. But despite apparent clear lines of responsibility and extensive systems evaluation, the conclusion of the appointed auditor in July 1992 was that there were serious failures in the management of RISP. Examples include:

- Serious failures in contract controls occurred:

"The 1986 contract with Andersen Consulting/IBM was approved at an inquorate meeting of the Information Group."

"The contract omitted clauses for quality provision and maximum price which had been provided for in the tender documents."

"The contract did not include a detailed specification for the proposed partnership arrangement for RISPs information technology function."

- Risk was further exacerbated by the WRHAs lack of consideration of qualitative measures such as experience, past performance and reputation, when awarded many of their contracts. Serious conflicts of interest at a senior level within the authority occurred and generally it was not established whether those suppliers recruited for the RISP project were the best available:

"A Member of WRHA who was also a Director of IBM, promoted the Andersen Consulting bid." This was because the Andersen Consulting bid involved the procurement of IBM software and terminals.

"The Region, who had employed Andersen Consulting as consultants to assist in the development of the RISP since 1983, appointed Andersen Consulting (in 1986) as advisors to a selection panel while they were bidding for the award of the main contract." They were subsequently awarded the contract for the selection of software for one of the core systems of the project.

\footnotetext{
"The Region awarded the contract to a company formed by Cipfa Facilities Management Ltd., which was majority owned by CSL Ltd., the company which initially recommended the partnership arrangement to the region."

"The region let a software contract to Computer Associates for 80,600 without competitive tenders or a full analysis. The software was never used."

"The original contract with Cipfa Services Ltd was awarded in November 1987 without proper tendering procedures."
} 
"The appointed auditor for RISP found no evidence that the region had undertaken a full evaluation of the alternative suppliers."

- Serious failings in the management of project staff occurred:

"The region's IT division's complement was 104, but only 60 staff were in post and transferred to Wessex Integrated Systems Ltd (which was leading RISP development). The Region's Chairman had not been made aware of this when he sought to minimise commercial risks to which the new company would be exposed."

- The lack of clear definition of the scope of RISP, in turn led to difficulties in budgeting for and controlling expenditure attributed to RISP. Financial control was not helped by inadequate Internal Audits for the RISP project were inadequate:

"Throughout the history of the regional information systems plan, Internal Audit failed to provide management with an adequate level of independent assurance as to the propriety of expenditure on the plan."

"The WRHA's budgetary control system was at best general and frequently non-existent. Detailed budgets were not calculated before the start of the financial year and when available were set at aggregate levels, often in millions of pounds. As such budgetary control would have been difficult if not impossible to operate. IT budget holders have stated that they had little control over the production or management of their budgets. They had assumed that this aspect was being undertaken by the Finance Function, which was to prove ill founded."

The end result was a massive over spending of the original RISP estimate of $£ 25.8$ million pounds with very little operational return.

\subsubsection{Summary:}

The Processes involved in these case studies have shown that there were many common flaws within the project management of LASCAD and RISP, involving poor contract and consultant control and ignorance of user issues. The cumulative effect of these flaws led to the eventual downfall of both projects. There is much to be learnt from the close examination of the pitfalls of these two well-known failures. Willcocks and Margett's risk assessment model and systems such as the new NHS Risk Register seek to help to feedback this information so that mistakes are not repeated by future developers and project managers introducing IS into the NHS.

\subsubsection{Risk Outcomes:}

Planned or unanticipated, desirable or otherwise, e.g. cost, time, technical performance, operational efficiency, user acceptance.

\subsubsection{The Wessex RISP:}

The development of RISP was formally abandoned in April 1990. Although development and implementation had started in 1986, little progress in the provision of five core systems to all ten districts had been achieved. Some six years after the tenders were first invited and after the expenditure of $£ 43$ million, the following progress had been achieved: 
- Hospitals: Only one hospital in the District (Winchester) has implemented a hospital IS. A further District, Bath, has recently decided to introduce the system. Initial licences and consultancy costing $£ 538,300$ and $£ 1.3$ million for West Dorset and Southampton respectively by the WRHA. However both Districts abandoned their plans because of the high cost of implementation and a lack of funds.

- Finance: The general ledger system has been provided in all Districts and the accounts payable in five Districts. Districts following the evaluation of the Purchase Order System against the existing systems preferred to retain their present systems, rejecting the Purchasing System.

- Personnel: Abortive expenditure totalling $£ 1.6$ million was incurred on software licenses ( $£ 0.5$ million) and consultancy fees ( $£ 1.1$ million), before the system was abandoned. No working systems were implemented. Subsequently IPS was adopted but as a result of substantial disagreement as to who was to pay for its introduction, several Districts declined to use it.

- Community Care: A feasibility study was completed at a cost to the authority of $£ 188,000$ but it was then abandoned.

- Interim Systems: The development of the interim systems were originally seen as a short term measure, to ensure the improvement of "current" information while the core systems were being developed. It was noted as early as 1984 that these interim systems "should only be enhanced where they could be cost justified." However, due to implementation delays and changes to applications, Districts came to rely on these systems. Substantial investment, almost \$15 million, was therefore diverted from the mainstream RISP development into the interim systems. However, by 1987 it was apparent that Interim system development was affecting the WRHA's ability to development of RISP.

\subsubsection{The LASCAD Project:}

Unlike RISP, the LASCAD was completed and made operational. When start-up occurred on 26 October 1992, the system was system was lightly loaded. Staff could effectively manage problems, caused particularly by the communications systems (such as ambulance crews pressing the wrong buttons or ambulances being radioed in blackspots). However, as the number of ambulance incidents increased, the amount of incorrect vehicle information recorded by the system increased. This had a knock-on effect in that the system made incorrect allocations on the basis of the information it had. For example, multiple vehicles were sent to the same incident, or the closest vehicle was not chosen for despatch. As a consequence, the system had fewer resources to allocate. The system also placed calls that had not gone through the appropriate protocol on a waiting list and generated exception messages for those incidents for which it had received incorrect status information. The number of exception messages appears to have increased to such an extent the staff were not able to clear the queue. It became increasingly difficult to attend to messages that had scrolled off the screen. The increasing size of the queue slowed the system. All this meant that it took longer to allocate resources to incidents.

At the receiving end, patients became frustrated with the delays to ambulances arriving at incidents. This led to an increase in the number of calls made back to the LAS HQ relating to already recorded incidents. The increased volume of calls, together with a slow system and an insufficient number of call-takers, contributed to significant delays in answering calls which, in turn, caused further delays to patients. At the ambulance end, crews became increasingly frustrated at incorrect allocations. This may have led to an increased number of instances where crews failed to press the right status buttons, or took a different vehicle to an incident than that suggested by the system. Crew frustration also seems to have contributed to a greater volume of voice radio traffic. This in turn contributed to the rising radio communications bottleneck, which caused a general slowing down in radio communications which, in 
turn, fed back into increasing crew frustration. The system therefore appears to have been in a vicious circle of cause and effect. In addition, it was claimed that a reorganisation of sector desks over the preceding weekend might have caused loss of local knowledge.

\subsubsection{Summary:}

Examining the Risk Outcomes of RISP and LASCAD serves to highlight the substantial financial cost failed IS projects inflict on a tightly resourced UK NHS. RISP also reflects the long period of time between the commencement (1984) and abandonment (1990) of large IS projects in the NHS. It appears that once a large IS project in the NHS begins to falter, it is a very difficult process to stop as more and more money is invested into retrieving the situation. The NHS is very committed once they begin projects to see them succeed. Therefore, the lesson uncovered here is that thorough analysis of the potential risks involved in IS projects, provided by a risk assessment model such as Willcocks and Margett's, would be an invaluable tool within the NHS.

\subsection{Summary Table:}

\begin{tabular}{|c|c|c|}
\hline $\begin{array}{l}\text { Willcocks \& Margett's } \\
\text { Risk Framework (1994) }\end{array}$ & $\begin{array}{l}\text { LASCAD } \\
\text { Summary }\end{array}$ & $\begin{array}{c}\text { RISP } \\
\text { Summary } \\
\end{array}$ \\
\hline $\begin{array}{l}\text { CONTENT } \\
\text { Despite the size and complexity } \\
\text { of both projects, LAS and RISP } \\
\text { adopted a radical approach }\end{array}$ & $\begin{array}{l}\text { Aim to automate human- } \\
\text { intensive processes of } \\
\text { despatch system }\end{array}$ & $\begin{array}{l}\text { Five major computer } \\
\text { systems, operating to } \\
\text { common standards and } \\
\text { operational in every district }\end{array}$ \\
\hline $\begin{array}{l}\qquad \text { HISTORY } \\
\text { Poor IS Policy in NHS coupled } \\
\text { with management restructuring }\end{array}$ & - Previous failed CAD project & - No previous IS experience \\
\hline INTERNAL CONTEXT & $\begin{array}{l}\text { - High risk involved in LAS } \\
\text { management structure and } \\
\text { staff relations }\end{array}$ & $\begin{array}{l}\text { - High risk IS strategy } \\
\text { and structure }\end{array}$ \\
\hline EXTERNAL CONTEXT & $\begin{array}{l}\text { NHS reforms on LAS } \\
\text { management failed, } \\
\text { worsening climate of } \\
\text { mistrust } \\
\text { NHS agenda for LAS too } \\
\text { aggressive and "fear of } \\
\text { failure" was detrimental } \\
\text { to LASCAD project }\end{array}$ & $\begin{array}{l}\text { - No clear national framework } \\
\text { for information management } \\
\text { - Responsibility of technology } \\
\text { procurement, project } \\
\text { management and budgeting } \\
\text { left to WRHA }\end{array}$ \\
\hline
\end{tabular}




\begin{tabular}{|c|c|c|}
\hline PROCESSES & $\begin{array}{l}\text { - } \text { Failed to follow PRINCE } \\
\text { - Software contract to } \\
\text { company with no previous } \\
\text { experience } \\
\text { - } \quad \text { Time pressure meant system } \\
\text { not fully tested } \\
\text { - User commitment issues } \\
\text { ignored } \\
\text { - Lack of staff training }\end{array}$ & $\begin{array}{l}\text { 1. Failure to control consultant } \\
\text { activities } \\
\text { 2. Serious conflicts of interest } \\
\text { within WRHA } \\
\text { 3. Failings in staff management } \\
\text { 4. Inadequate budgeting } \\
\text { control system }\end{array}$ \\
\hline OUTCOMES & $\begin{array}{l}£ 1 \text { million spent, but LASCAD } \\
\text { failed soon after implementation }\end{array}$ & $\begin{array}{l}£ 43 \text { million spent for little } \\
\text { progress in RISP project }\end{array}$ \\
\hline
\end{tabular}

Figure 2: Summary of application of Willcock and Margett's framework on LASCAD and RISP. 


\subsection{General Case study Evaluation:}

Willcocks and Margett's model demonstrates how the large-scale failures of RISP and LASCAD were due to several prominent organisational risks inherent in their history, context, and processes. The neglect of these organisational risks in the original attempts to implement both systems contributed directly to their failures. Many similarities were seen in the way that Wessex Regional Health Authority (WRHA) and the London Ambulance Service (LAS) mis-managed and mis-interpreted organisational risks, which led to the demise of the systems projects. Both opted for an over-ambitious approach and project strategy and not only had poor project management, but a lack of both consideration of user issues and adequate staff training. This ambitious approach and lack of expertise would have been difficult to overcome in the most ideal circumstances, but especially in the face the unstable political context due to the NHS management reforms. The management reforms were to backfire and instead of bringing improvements they had a damaging effect on the culture and internal structures of both WRHA and LAS work environments. Now was a time to be as cautious as possible but instead these two health bodies went for radical approaches to their systems development and implementation, disregarding the heightened organisational risks. The political and economic context of the NHS also clearly influenced the shape of the organisation's computing, including most of the information systems projects conducted within the remit of the organisation. RISP and LASCAD projects suffered directly from poor NHS information systems policy and co-ordination which lead to them being subjected to undue time pressures in implementation.

Although, Willcocks and Margett's model can not remove the risks inherent in the organisational context it is helpful in 'bringing them to the surface'. This could prove useful in order to present a more realistic picture of the organisation within which the system will have to exist and the limitations and resource constraints that the system will have to be implemented within. The model is also useful in that it sees risk as not just inherent in certain structural features of the environment or of a project, but also arising over time from their interconnection with history, process and internal context as a result of distinctive human and organisational practices and patterns of belief and action. Willcocks and Margetts have developed a more process-oriented and organisation studies-based framework for risk analysis and management which may prove a useful tool for major NHS and other public sector information systems projects. The lesson learnt from RISP and LASCAD is that very expensive and damaging consequences result if the organisational risks surrounding a project are not fully accounted for or controlled.

\subsection{Advantages of Willcocks And Margett's Model:}

Willcocks and Margetts have developed a process-oriented and organisation-based model for risk analysis and management. It's great advantage comes from the fact that it forces IS designers and managers to properly evaluate the risks that arise from the environment within which the IS project will reside. This is particularly important because the NHS is a changing, evolving organisation. "New" concepts such as Business Process Engineering and Organisational Learning Theory are being introduced into the NHS to improve performance and efficiency. They will undoubtedly change the structure and culture of the environment within which IS projects will reside and, therefore, it is crucial that IS projects are adapted to these new NHS contexts. 


\subsection{Disadvantages:}

The use of Willcocks and Margett's model uncovered many relevant organisational risks involved in NHS IS projects, and so could be a useful tool in the re-design and re-implementation of these systems in the future. But it was applied here post hoc and so it is unknown whether it can be used as an a-priori analysis. It is envisaged Willcocks and Margett's model will provide preventative actions to organisations and derive recommendations for redesign, and not simply act as an after the fact assessment. Consequently, it must be validated as a design technique. This is a not an easy task. Beyer and Holtzblatt (1998) reveal that "History is littered with excellent innovations solving real problems that have never been adopted because it is simply too hard to switch models." For the model to support design improvements, it requires a wider contextual analysis reflecting the fact that it is often difficult to adapt new techniques and models to users and their environment.

Further concerns arise from the subjective nature of our analysis. Others might derive quite different results from the application of Willcocks and Margett's model to our two case studies. However, the key point is that this approach provides a common starting point for an analysis of organisational failures in IS projects.

Another drawback of the Willcocks and Margett's model is that it does not include a measure of change. Once implemented an IS changes the environment in which it is placed, and therefore the organisational risks that the system is subjected to also differ. At present Willcocks and Margett's model does not deal with this organisational change. It would seem advantageous to carry out this type of risk assessment throughout the lifecycle of the IS, through the initial design phase, development and user testing/prototyping, implementation and when the system is operational. Therefore, by carrying out Willcocks and Margett's before and after the IS is implemented it will be possible to demonstrate how the IS changes the organisation. A further point here is that the model will have to be adapted to each stage of the overall development process as the environment and context will change as new organisational risks are introduced and others become obsolete.

\subsection{Other British Public Sector IS Failures:}

Before concluding the arguments in this paper, it should be noted that there have been many other notable IS failures within the British public sector in recent years. These have similarly utilised large sums of public funds and resources. These include the collapse of the UK Passport Agency system in the summer of 1999 and the scrapping of the Immigration and Nationality Directorate Casework Programme later that same year. Both systems suffered embarrassing backlogs and insurmountable problems, which led to their abandonment. Most recently, in February 2001, the implementation of the National Probation Service Information Systems Strategy (NPSISS) and specifically, the Case Recording and Management System (CRAMS) was terminated.

On the 15th of February 2001 Simon Hughes MP, Liberal Democrat Shadow Home Secretary, released information obtained through parliamentary questions which show that the CRAM system is not the only IT project that has been causing problems for the Home Office this year. Of 11 IT projects currently being carried out by the Home Office, 8 of them were either seriously delayed, seriously over budget or both. Combined the IT projects are at least $£ 41$ million over budget and 11 years late. Specifically, the new Passport Agency IT system, after the 1999 collapse, has still not been fully rolled out and is yet to be implemented in the London, Belfast and Glasgow Offices. Already though it is $£ 38$ million over its original planned cost. The Asylum Support IT Project is expected to be two years late 
and $£ 2.2$ million over budget, and IT for the new Criminal Records Bureau from the Home Office information appears to be almost double the original planned cost. So, the reality of this $72 \%$ IT failure is that ministers are clearly failing to learn the lessons of past failures.

These other examples reveal that IT development is a learning process and prove to highlight that this paper has not sought to target the NHS as mismanaging IS projects. It is the uniqueness of the NHS as an organisation and its constantly changing organisational dynamics that makes it an interesting case study. More importantly, the fact that the recent government Information for Health document emphasised the expansion of the use of IS throughout the NHS, invites a reassessment of the way that risk in IS projects is dealt with. The overall aim is to maximise the benefit of the use of IS in British healthcare for improved patient treatment.

\section{Conclusion:}

By demonstrating that the large-scale failures of RISP and LASCAD were due to neglect of major risks inherent in their history, context, and processes, Willcocks and Margett's (1994) model highlights the importance of organisational issues in the development and implementation of IS projects in the NHS. IS projects can not succeed without comprehensive consideration of the organisational, social and political factors. As the RISP and LASCAD case studies have powerfully shown, the implementation of IS strategy implies considerable change in the current ways of working, facilitating the requirement that all staff are trained and given time to adapt to a new work environment. Underlying all IS strategy is a need for commitment to the crucial role of the user. Without adequate education and training of users to support their adaptation to the new technology, an IS project can not be expected to achieve its full potential, and may indeed fail as RISP and LASCAD demonstrated. This serves as only one example that neglect of organisational issues by IS designers and project managers is detrimental to overall project success.

Of course understanding the organisational issues should not deflect from the importance of the technical aspects of development and testing of the system and ensuring that risks involved with technical factors are controlled. Rather, there is a need in the NHS to address the multi-factorial nature of IS failure. It is essential that the NHS address the risks that are generated from the user, technology and the organisation. The use of this kind of formalised risk assessment model, applied in hind sight, has been shown to be helpful in highlighting the varied risks in the 6 inter-playing categories involved in IS projects.

This paper therefore advocates the use of this kind of risk model, which takes into account context, history and organisational processes, in the design phase of IS projects. In this way, it will help to make designers and project managers more aware of the inherent risks involved in IS projects and enable them to more effectively deal with these risks to increase the chances of IS project success. The impetus for such a scheme comes from the great need within the NHS to improve the success rate of IS implementation, in order to capitalise on the advantages that effective information management can bring to the improvement of the entire healthcare system and hence patient treatment. It is important though, to support the risk assessment process with a number of now widely available financial estimates and statistical techniques (Hull, 1990; Post \& Dilz, 1986; Williams, 1990). Also, the pure scale of the NHS, it employs 1 million staff with 100 Health Authorities and 400 NHS trusts, must be remembered. This means that applicability of any new risk tool with be problematic if it is not adequately supported throughout the different organisational levels. 


\section{References:}

1. Appleton D. Very Large Projects. Datamation, pp.63-70, 15 January 1991.

2. Barber B. The European approach to standards in medical informatics. In F. Redmill et al. (eds). Safety-critical systems: Current issues, techniques, and standards. Chapman and Hall, Cornwall, 1993, pp.238-255.

3. Barriere M, Cooper S, Forester J, Kolaczkowski A, Lucas W, Parry G, Ramey-Smith A, Thompson C, Whitehead D, Wreathall J. Technical Basis and Implementation Guidelines for A Technique for Human Event Analysis (ATHEANA), NUREG-1624, US-NRC. Washington DC, 1998.

4. Beynon-Davis P. Human error and information systems failure: the case of the London Ambulance service computer-aided despatch system project. Interacting with Computers 1999; 11: 699-720.

5. Beynon-Davis P. Information Management in the British National Health Service: The Pragmatics of Strategic Data Planning. International Journal of Information Management 1994;14(2): 84-94.

6. Bieder C, Le-Bot P, Desmares E, Bonnet J-L, Cara F. MERMOS: EDF's New Advanced HRA Method, in Probabilistic Safety Assessment and Management. In A. Mosleh et al. (eds). PSAM 4.a curi di. Springer, London, 13-18 September 1998.

7. Buchanan D. Figure-ground reversal in systems development \& implementation: From HCI to OSI. In Nurminen $\mathrm{M}$ et al (eds). Human Jobs and Computer Interfaces. North Holland, Amsterdam, pp.213-226.

8. Bourn J. Managing Computer Projects in the National Health Service. HC22, 1990-1991.

9. Cash J, McFarlan W, McKenney J. Corporate Information Systems Management. Irwin, Boston, 1992.

10. Clegg C, Warr P, Green T, Monk A, Allison G, Lansdale M. People and Computers: How to Evaluate your Company's New Technology. Ellis Horwood, Chicester, 1989.

11. Clegg C, Waterson P, Clarey N. Computer supported collaborative working: lessons for elsewhere. Journal of Information technology 1994; 9:85-98.

12. Clegg C, Axtell C, Damodaran L, Farbey B, Hull R, Lloyd-Jones R, Nicholls J, Sell R, Tomlinson C. Information technology: a study of performance and the role of human and organisational factors. Ergonomics 1997; 40: 851-871.

13. Collingridge D. The Management of Scale. Routledge, London, 1992.

14. Corder C. Taming your Company Computer. McGraw-Hill, London, 1989.

15. Davidson F, Huot J.C. Large-scale Projects: Management Trends for Major Projects. Cost Engineering 1991; 33(2): 15-23. 
16. Dingwall R, Fenn P (1995). Risk management: financial implications. In: Vincent C (ed.). Clinical risk management. London: BMJ Publishing Group.

17. Doherty N, King M. The consideration of organisational issues during the systems development process: an empirical analysis. Behaviour and Information Technology 1998; 17(1): 41-51.

18. Earl M.J. Management Strategies for Information Technology. Prentice Hall, Hemel Hempstead, 1989.

19. Eason K. Information Technology and Organisational Change. Taylor \& Francis, London, 1988.

20. Evans D. Where next for the hospital clinical claims manager? Clinical Risk 1998; 4: 66-68.

21. Ewushi-Mensah K, Przasnyski Z. Factors contributing to the abandonment of information systems development projects. Journal of Information Technology 1994; 9: 185-201.

22. Griffiths Report. Report of the NHS Management Inquiry. (D38) 38, HMSO, London, October, 1983.

23. Hammer W. Handbook of System and Product Safety. Prentice-Hall Inc., New Jersey, 1972.

24. Hochstrasser B, Griffiths C. Controlling IT Investments: Strategy and Management. Chapman and Hall, London, 1991.

25. Hornby C, Clegg C, Robson J, McClaren C, Richardson S, O-Brien P. Human and organisational issues in information systems development. Behaviour and Information Technology 1992; 11: $160-174$.

26. Hull J. Application of Risk Analysis Techniques in Proposal Assessment. Project Management 1990; 8(3):152-157.

27. Johnson C.W. Representing the Impact of Time on Human Error and Systems. Interacting with Computers, 1998; 11: 53-86.

28. Kearney A.T. Barriers to the Successful Application of Information Technology. Department of Trade and Industry, London, 1990.

29. Keen P. Shaping the Future. Harvard Business Press, Boston, 1991.

30. KPMG International. Project Risk Management: Infomation Risk management document. June, 1999.

31. Leveson N. Software Safety. Communications of the ACM, 1991; 34(2): 35-46.

32. Leveson N. Safeware: System Safety And Computers: A Guide To Preventing Accidents And Losses Caused By Technology. Addison Wesley, USA, 1995.

33. Long R. J. New Office Information Technology: Human and Managerial Implications. Croom 
Helm, London, 1987.

34. Loudon K, Loudon J. Management Information Systems: A Contemporary Perspective. Macmillan, New York, 1991.

35. Lyytinen K, Hirscheim R. Information systems failure: A survey and classification of the empirical literature. Oxford Surveys in Information Technology 1987; 4: 257-309.

36. Lyytinen K, Robey D. Learning failure in information systems development. Journal of Information Systems 1999; 9: 85-101.

37. McKenzie D. Computer-related accidental death: an empirical exploration. Science and Public Policy 1994; 21: 233-248.

38. Morris P, Hough G. The Anatomy of Major Projects. John Wiley and Sons, Chichester, 1987.

39. NHS Executive. Working for Patients: Framework for Information Systems: The Next Steps. HMSO, London, 1989.

40. NHS Executive. NHS Community Care Act. HMSO, London, 1991.

41. NHS Executive. The Information Management and Technology (IM\&T) Strategy for the NHS in England: Getting Better with Information. Department of Health, Leeds, 1992.

42. NHS Executive. Information for Health: An Information Strategy for Modern NHS 1998-2005. NHSE, Leeds, 1998.

43. NHS Executive. Guidelines For Implementing Controls Assurance In The NHS. NHSE, Leeds, 1999.

44. Overview of Failure Modes, Effect and Criticality Analysis (FMECA) Methodology and Software. Current WWW document. URL page: http://www.fmeca.com/

45. Parker M, Benson R, Trainor E. Information Economics: Linking Business Performance to Information Technology. Prentice-Hall, New Jersey, 1998.

46. Pettigrew A, Whipp R. Managing Change for Competitive Success. Basil Blackwood, London, 1991.

47. Pettigrew A, Ferlie E, McKee L. Shaping Strategic Change. Sage, London, 1992.

48. Pike R, Ho S. Risk Analysis in Capital Budgeting: Barriers and Benefits. Omega 1991; 19(4): 235-245.

49. Post G, Dilz D. A Stochastic Dominance Approach to Risk Analysis of Computer Systems. MIS Quarterly 1986; December:362-375.

50. Redmill F, Chudleigh M, Catmur J. System Safety: HAZOP and Software HAZOP. John Wiley 
and Sons, Chichester, 1999.

51. Scott-Morton M. The Corporation of the 1990s. Oxford University Press, Oxford, 1991.

52. Secretary of State for Health. The New NHS - Modern and Dependable. CM 3807, HMSO, London, December 1997.

53. Suokas J, Rouhiainen V. Quality control in safety and risk analysis. Journal of Loss Prevention in Process Industry, 1989; 2: 67-77.

54. Swain A. D, Guttman H.E. Handbook of Human Reliability Analysis with Emphasis on Nuclear Power Plant Application. NUREG/CR-1278, 1983.

55. Thames Regional Health Authority: Report of the Inquiry into the London Ambulance Service. The Communications Directorate, South West Thames Regional Health Authority. ISBN No: 0905133 706, February 1993.

56. Wessex Regional Health Authority Regional Information Systems Plan. Committee of Public Accounts Sixty-third Report, House of Commons. HMSO, London, Session 1992-1993.

57. Willcocks L, Griffiths C. Management and Risk in Major Information Technology Projects. In Willcocks et al (eds). Managing IT as a Strategic Resource. McGraw-Hill, London, 1997, pp.203-237.

58. Willcocks L, Margetts H. Risk assessment and information systems. European Journal of Information Systems 1994; 3(2): 127-138.

59. Willcocks L. Of Capital Importance: Evaluation and Management of Information Systems Investments. Chapman and Hall, London, 1993.

60. Willcocks L. (ed.) Information Management: The Evaluation of Information Systems Investments. Chapman and Hall, London, 1994.

61. Willcocks L. (ed.) Investing in Information Systems: Evaluation And Management. Chapman and Hall, London, 1996.

62. Williams T. Risk Analysis Using an Embedded CPA Package. Project Manangement 1990; 8(2): 84-88. 